\title{
Design and Analysis for Robust PID Controller
}

\author{
Jagriti Pandey $^{1}$, Aashish Hiradhar ${ }^{2}$ \\ Department of Electrical and Electronics Engineering, C..V.Raman University Bilaspur \\ Department of Electrical and Electronics Engineering, C..V.Raman University Bilaspur
}

\begin{abstract}
This paper presented a robust PID controller design for time delay system. Utilizing the gain-phase margin tester method, a specification-oriented parameter region in the parameter plane that characterizes all admissible controller coefficients sets can be obtained. The PID controller gains are then directly selected from the parameter region. And the designed controller can guarantee the system at least a pre-specified safety margin to compensate for instability induced by time delay. A compromise between the performances of the system with the above mentioned and smith predictor is also included. The simulations are carried by TRUETIME network simulator for virtually implementation of NETWORKED CONTROL SYSTEM. The simulation results proves the mentioned PID controller is performs good time response and also compensate the delay is obtained efficiently.
\end{abstract}

Index Terms: Non-minimum phase system, network control system, delays Compensation, gain margin, phase margin, PID controller, and Distributed system.

\section{Introduction}

The point-to-point communication architecture has been successfully used in industry for decades for control system implementation. Expanding physical setups and functionality, however, are pushing the limits of the point-to-point architecture. Hence, such centralized point-to-point control systems are no longer suitable to meet new requirements such as modularity, decentralization of control, integrated diagnostics, quick and easy maintenance, and low cost. But technology advances and the availability of network connectivity have prompted the idea of introducing network facilities to Control systems. When PID controllers receive the sensor information or transmit its output through a communication network, its parameters are difficult to tune using classical tuning methods; this is due to the delays introduced by the network. This paper presents the ZieglerNichols closed loop cycling methods for tuning the various parameter of a system. Now a day there is a trend in the research of control theory to investigate control loop that are stretched over a network.

\section{Distributed System}

In distributed systems the controller and the process are physically separated and connected with a network. Their sensors, actuators, estimator units, and control units are connected through communication networks. This type of system provides several advantages such as modular and flexible system design,simple and fast implementation, and powerful system diagnosis and maintenance utilities.

The disadvantage is that the analysis and design of an distributed system becomes complex Distributed system is shown in fig.1.

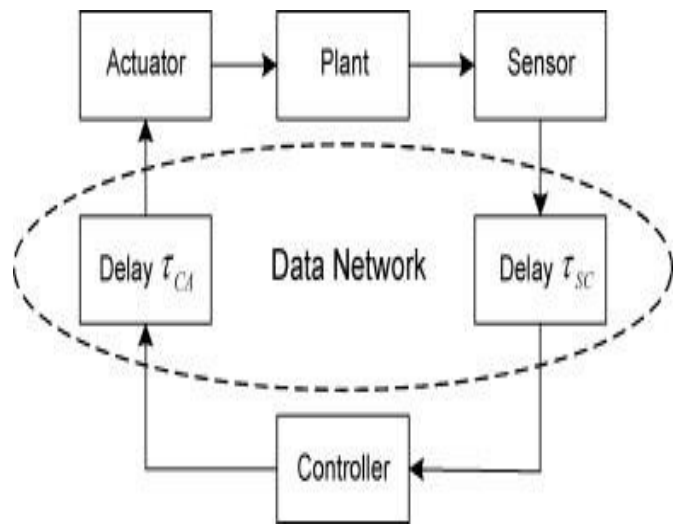

Figure 1. Distributed System

Fig (2) shows the timing diagram of network delay propagation. Delay in an NCS can be divided into different types on the basis of data transfers i.e., 
i) sensor to controller delay

ii) controller to actuator delay.

2. Increase the value of the proportional gain until the point of instability is reached, the critical value of gain $\mathrm{K}_{\mathrm{C}}$ is reached.

3. Measure the period of oscillation to obtain the critical time constant, $\mathrm{T}_{\mathrm{c}}$.

Once the values for $K_{C}$ and $T_{C}$ are obtained, the PID parameters Can be calculated, according to the

Design specification given in Table-1.

Table -1

\begin{tabular}{|l|l|l|l|}
\hline Control & KP & KI & KD \\
\hline P & $0.5 \mathrm{~K}_{\mathrm{C}}$ & & \\
\hline PI & $0.45 \mathrm{~K}_{\mathrm{C}}$ & $1.2 \mathrm{~T}_{\mathrm{C}}$ & \\
\hline PID & $0.33 \mathrm{~K}_{\mathrm{C}}$ & $2 \mathrm{~T}_{\mathrm{C}}$ & $0.33 \mathrm{~T}_{\mathrm{C}}$ \\
\hline
\end{tabular}

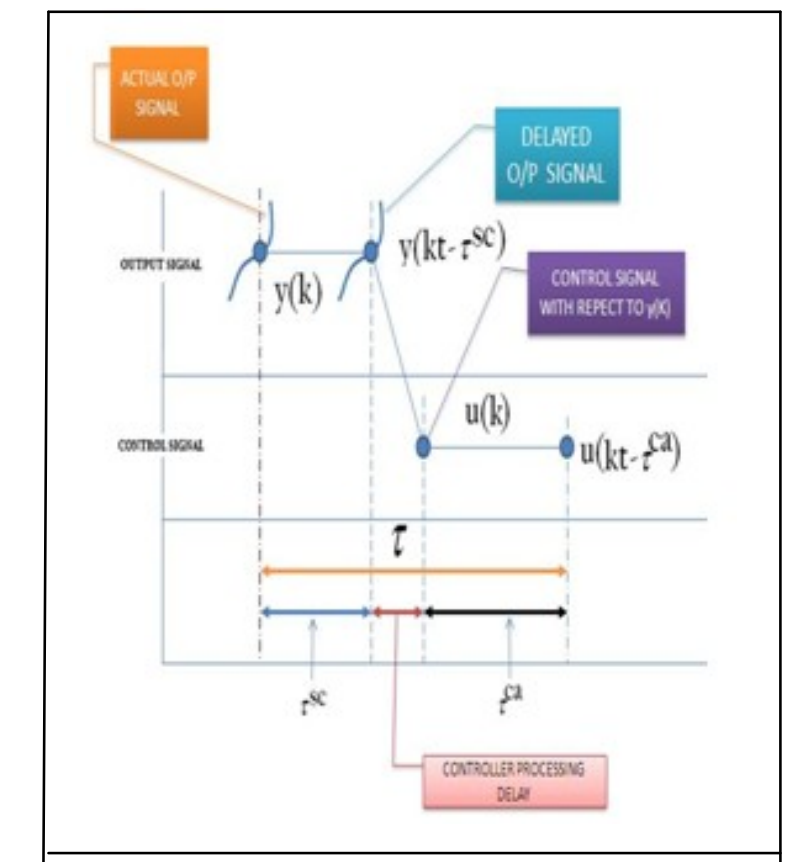

Figure2. Timing diagram of Network delay propagations

\section{Pid Conroller In Nes}

The PD controller could add damping to a system, but steady state response is not affected. The PI controller could improves the relative stability and improves the steady state error at the same time, but the rise time is increased.This leads to the motivation of using PID controller so that the best features of each of PI and PD controllers are utilized. The PID Control is one of the most popular control strategies for process control because of its simple control structure and easy tune

.The transfer function of PID controller is

$\mathrm{G}_{\mathrm{C}}(\mathrm{s})=\mathrm{K}_{\mathrm{P}}+\mathrm{K}_{\mathrm{D}} \mathrm{S}+\underline{\kappa_{I}} \quad s$

Where,

$\mathrm{K}_{\mathrm{P}}=$ proportional gain constant,

$\mathrm{K}_{\mathrm{I}}$ Integral gain constant,

$\mathrm{K}_{\mathrm{D}}=$ Derivative gain constant, 
The PID controller is traditionally suitable for second and lower order systems. It can also be used for higher order plants with dominant second order behaviour. In this paper we used Ziegler -Nichols closed loop cycling method and gain margin, phase margin tester methods for PID controller tuning.

Ziegler- Nichols closed loop cycling methods: Procedure for tuning

1. Select proportional control alone.

2 .

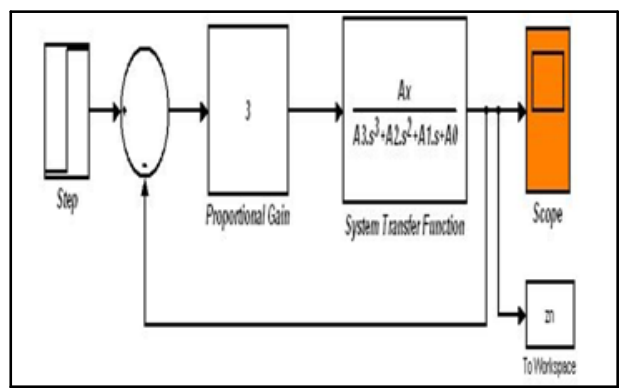

Figure 3. Simulink Model for Z-N Tuning PID Controller

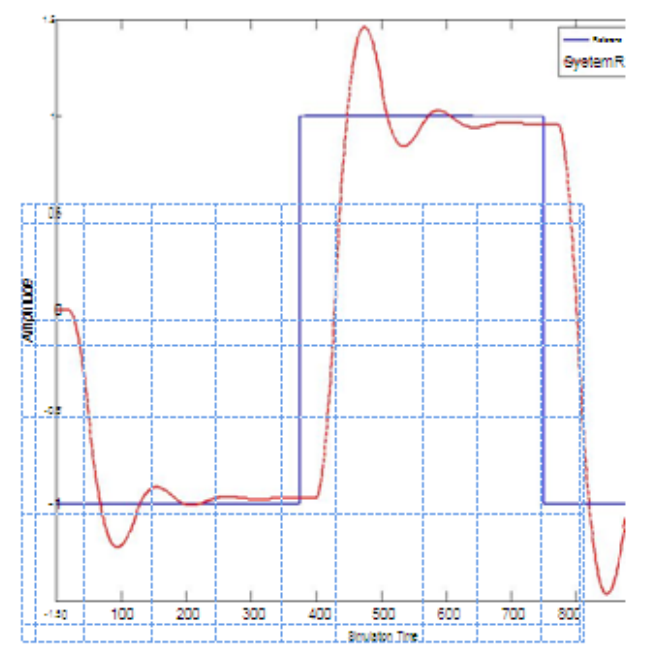

Figure 4. PID controller response with Z-N tuning and no delay

The PID Controller is suitable for second and lower order system and when delays is introduce in the system, performance of the system is degraded and also de-stabilized the system by reducing the system stability margin, thus a Robust PID Controller design is introduced in this paper for higher order non-minimum system which contains the time delay element

\section{A Robust Pid Controller Design:}

Whenever there is a delay between the commanded response and the start of the output response time delay occurs in the control system which decreases the phase margin and lowers the damping ratio and hence increases the oscillatory response for the closed loop system. Time delay also decreases the gain margin, thus moves the system closer to the instability.

In this paper, suitable algorithms are introduced for the instability induced by the time delays. For a high -order non -minimum phase system which contains the time delay element, whose transfer function is as shown.

$$
\begin{aligned}
& A X \\
& \text { Transfer function } \\
& = \\
& \text { Where, } T \text { is the delay time of the } \\
& \text { system. }
\end{aligned}
$$




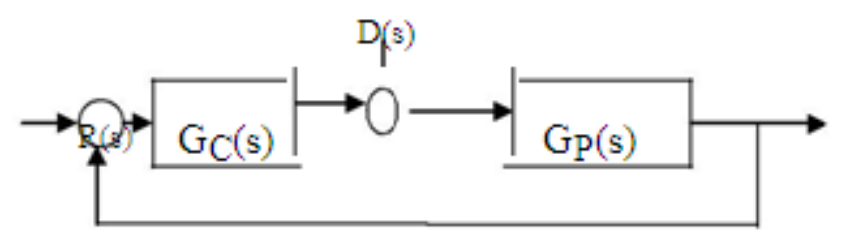

Figure 5. Block Diagram of a Typical PID Control System

An error-actuated PID controller has the general transfer function

$\mathrm{G}_{\mathrm{C}}(\mathrm{s})=\mathrm{K}_{\mathrm{P}}+\mathrm{K}_{\mathrm{D}} \mathrm{S}+{ }_{\mathrm{S}} \underline{\mathrm{Ki}}$

(2)

The forward open-loop transfer function of the control system shown in Fig. 5 is

$\mathrm{G}_{0}(\mathrm{~S})=\mathrm{G}_{\mathrm{C}}(\mathrm{S}) \cdot \mathrm{G}_{\mathrm{P}}(\mathrm{S}) \underset{D(S)}{=N(S)}$

(3)

$j \omega$

By letting $\mathrm{S}=$, and $\operatorname{Re}\left[\mathrm{G}_{0}(j \omega)\right]$ and Imaginary $\left[\mathrm{G}_{0}(\quad)\right]$ be the real part and imaginary part of

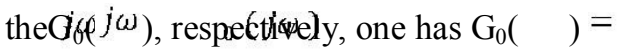

IG

$1 e^{j} \phi$

(4)

Where,

$\left|G_{0}(j \omega)\right|=$

$\sqrt{\operatorname{Real}\left[G_{0}(j \omega)\right]^{2}+\operatorname{Img}\left[G_{0}(j \omega)\right]^{2}}$

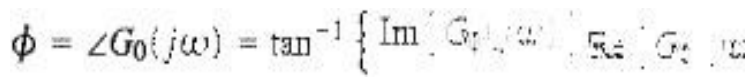

(6)

Substituting (4) and (3), one obtains

$D(j \omega)-\frac{1}{G_{0}(j \omega) \text { e. }} N(\omega=)$.

(7) Let

$\mathrm{A}=\frac{}{G 0(j \omega)}$

(8)

$\theta=\varphi+180$.

(9)

When $\theta=0$, $A$ is the gain margin of the system, and when $A=1, \theta$ is the corresponding phase margin. Now we define the gain-phase margin tester function as,

$\mathrm{F}()=\mathrm{D}(j \omega)+A \quad-j \theta \mathrm{N}()(10)$

(7), (8), (9) and (10) imply that the function F ( $i \omega$ ) should always be equal to zero. This indicates that the gain margin and the phase margin of the PID control system can be determined from the characteristic equation.

plant transfer function

$=\frac{A x}{s^{3}+A 2 s^{2}+A 1 s+A 0}$

The open loop transfer function defined as 
$\underline{\mathrm{k}_{\mathrm{p}} s+\mathrm{k}_{\mathrm{i}}+\mathrm{k}_{\mathrm{D}} \mathrm{s}^{2}} \times$

$\frac{s=}{s^{3}+A 2 s^{2}+A 1 s+A 0} e^{-T s}$

putting $\mathrm{s}=j \omega$ and Noting that $A \quad-j \theta=\mathrm{A} \cos \quad \theta$ -

$j \mathrm{~A} \sin \theta$,

$$
\begin{aligned}
\mathrm{N}(j \omega)=, \mathrm{k}_{\mathrm{p}} \mathrm{j} \omega+\mathrm{k}_{\mathrm{i}}+\mathrm{k}_{\mathrm{d}}(\mathrm{j} \omega)^{2}, \times A x \times e_{-T} \mathrm{j} \omega \\
=A x(\cos \omega \mathrm{T}-\mathrm{j} \sin \omega \mathrm{T}) \times\left(j \mathrm{k}_{\mathrm{p}} \omega+\mathrm{k}_{\mathrm{i}}-\mathrm{k}_{\mathrm{d}} \omega^{2}\right) \\
=A x\left[\cos \omega \mathrm{T}\left(\mathrm{k}_{\mathrm{i}}-\mathrm{k}_{\mathrm{d}} \omega^{2}\right)+\sin \omega \mathrm{T}\left(\mathrm{k}_{\mathrm{p}} \omega\right)\right. \\
+\mathrm{j}\left\{\cos \omega \mathrm{T}\left(\mathrm{k}_{\mathrm{p}} \omega\right)\right. \\
\left.\left.-\sin \omega \mathrm{T}\left(\mathrm{k}_{\mathrm{i}}-\mathrm{k}_{\mathrm{d}} \omega^{2}\right)\right\}\right]
\end{aligned}
$$

Let us define

$\mathrm{X}_{\mathrm{N}}=\cos \omega \mathrm{T}\left(\mathrm{k}_{\mathrm{i}}-\mathrm{k}_{\mathrm{d}} \omega^{2}\right)+\sin \omega \mathrm{T}\left(\mathrm{k}_{\mathrm{p}} \omega\right)$

and $\mathrm{Y}_{\mathrm{N}}=\cos \omega \mathrm{T}\left(\mathrm{k}_{\mathrm{p}} \omega\right)$

$$
-\sin \omega \mathrm{T}\left(\mathrm{k}_{\mathrm{i}}-\mathrm{k}_{\mathrm{d}} \omega^{2}\right)
$$

$A e^{j \theta} \mathrm{N}(j \omega)=(A \cos \theta-\mathrm{j} A \sin \theta)\left(A x \mathrm{X}_{\mathrm{N}}+\mathrm{jAx} \mathrm{Y}_{\mathrm{N}}\right)$

$j\left(A \cos \theta Y_{N}-\right.$

$$
=A x\left[\left(A \cos \theta X_{N}+A \sin \theta Y_{N}\right)+\right.
$$

$\left.\left.A \sin \theta \mathrm{X}_{\mathrm{N}}\right)\right]$

$$
\begin{gathered}
D(j \omega)=j \omega\left((j \omega)^{3}+A 2(j \omega)^{2}+A 1 j \omega+A 0\right) \\
=\omega^{4}-j A 1 \omega^{4} \\
-j\left(A 2 \omega^{3}\right. \\
-A 0 \omega)
\end{gathered}
$$

Let us define

$$
\begin{aligned}
X_{D}=\left(\omega^{4}-A 1 \omega^{2}\right) \text { and } Y_{D} \\
=\left(A 2 \omega^{3}-A 0 \omega\right)
\end{aligned}
$$

real parts:

$\left(\omega^{4}-A 1 \omega^{2}\right)+A x A \cos$

$$
\begin{aligned}
& +A x A \sin \theta\left\{\cos \omega T\left(\mathrm{k}_{\mathrm{p}} \omega\right)\right. \\
& -\sin \omega \mathrm{T}\left(\mathrm{k}_{\mathrm{i}}\right. \\
& \left.\left.-\mathrm{k}_{\mathrm{d}} \omega^{2}\right)\right\}
\end{aligned}
$$

Define:-

$$
\begin{gathered}
B 1=(A x A \cos \theta \times \sin \omega \mathrm{T} \times \omega) \\
+(A x A \sin \theta \times \cos \omega \mathrm{T} \times \omega) \\
\quad=A x A \omega \sin (\theta+\omega \mathrm{T}) \quad(19) \\
C 1=(A x(A \cos \theta \times \cos \omega \mathrm{T})-(A x A \sin \theta \times \\
\sin \omega \mathrm{T}) \quad \\
=A x A \cos (\theta+\omega T) \\
D 1=\omega^{4}-A 1 \omega^{2}-A x A \cos \theta \times \cos T \omega^{2} \times \mathrm{k}_{\mathrm{d}} \\
+A x A \sin \theta \times \sin \omega \mathrm{T} \times \omega^{2} \mathrm{k}_{\mathrm{d}} \\
=\omega^{4}-A 1 \omega^{2} \\
-A x A \omega^{2} \mathrm{k}_{\mathrm{d}} \cos (\theta+\omega T)
\end{gathered}
$$

Then we can write from (10), (18), (19), (20), and (21) as

$$
\mathrm{k} \quad \mathrm{B} 1+\mathrm{k}_{\mathrm{i}} \mathrm{C} 1+\mathrm{D} 1=0(22)
$$

Imaginary parts:

$$
\begin{aligned}
\left(A 2 \omega^{3}-A 0 \omega\right) & +A x\left(A \operatorname { c o s } \theta \left[\cos \omega T\left(\mathrm{k}_{\mathrm{p}} \omega\right)\right.\right. \\
& \left.-\sin \omega T\left(\mathrm{k}_{\mathrm{i}}-\mathrm{k}_{\mathrm{d}} \omega^{2}\right)\right] \\
& -\left(A \operatorname { s i n } \theta \left[\cos \omega T\left(\mathrm{k}_{\mathrm{i}}-\mathrm{k}_{\mathrm{d}} \omega^{2}\right)\right.\right. \\
& \left.\left.+\sin \omega T\left(\mathrm{k}_{\mathrm{p}} \omega\right)\right]\right)
\end{aligned}
$$

$\mathrm{B} 2=(A x A \cos \theta \times \cos \omega \mathrm{T} \times \omega)_{-}(A x A \quad \sin \theta \times$ $\sin \omega \mathrm{T} \times \omega)$

$$
=A x A \omega \cos (\theta+\omega T)
$$


(24)

$\mathrm{C} 2=\left(-A x(A \cos \theta \times \sin \omega \mathrm{T}) \_(A x A \sin \theta \times\right.$

$\cos \omega \mathrm{T})$

$=-A x A \sin (\theta+\omega T)$

(25) $\left.\mathrm{D} 2=-A 2 \omega^{3}+A 0\right)+A x A \cos \theta \times \sin \omega T \times$

$\omega^{2} k_{d}+$

$A x A \cos \omega^{2} k_{d}$

Then we can write from (10), (23), (24), (25), and (26):- $\mathrm{k} \mathrm{B} 2+\mathrm{k}_{\mathrm{i}} \mathrm{C} 2+\mathrm{D} 2=0$

Solving the equations (22) and (27), we can find:- $\mathrm{k}=\underline{\mathrm{C} 1}$ (28)

\section{Simulation Results}

The simulation is carried out in MATLAB and SIMULINK .With the help of robust PID controller system stability is achieved and the system with delay gets stable and gives high degree of performance as shown in fig (6)
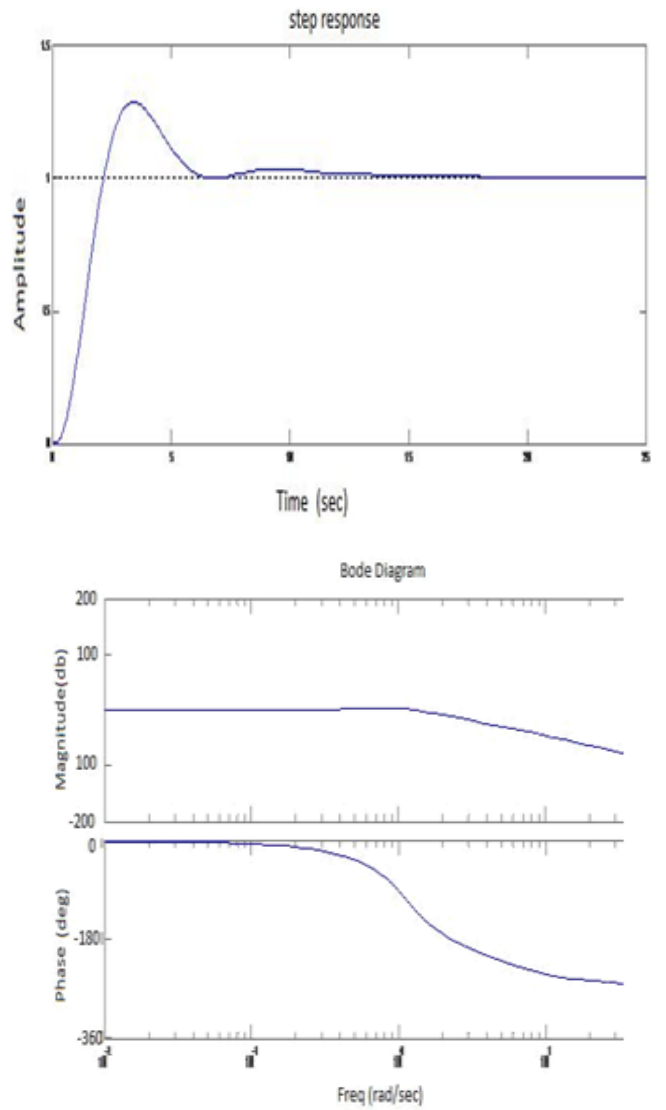

Figure6. Frequency and phase response of a system

\section{Conclusion}

The robust PID controller with certain variation in algorithms has made the system stabilized though various types of delays are present in the system. The advantage of this method is the guaranteed robustness with respect to plant variation and external disturbances. It promises the control system with good tracking and disturbance rejection behaviour. This method of achieving stability and good performance can be applied to the wide range of industrial applications. 


\section{References}

[1]. Ying J. Huang And Yuan-Jay Wang. Robust Pid Controller Design For Non-Minimum Phase Time Delay Systems, Isa Transactions 40(2001)31-39

[2]. A.M. De Paor And M. O'mally, Controllers Of Ziegler-Nichols Type For Unstable Process With Time Delay.Int. J.Ofcontrol49 4 (1989), Pp. 1273-1284.

[3]. A.T. Shenton And Z. Shafiei, Relative Stability For Control Systems With Adjustable Parameters.J.Ofguidance, Control And Dynamics17 (1994),Pp. 304-310.

[4]. W.K. Ho And W. Xu, Pid Tuning For Unstable Processes Based On Gain And Phase-Margin Specifications.Iee Proc.Controltheory And Appl145 5 (1998),Pp. 392-396.

[5]. C.H. Chang And K.W. Han, Gain Margins And Phase Margins For Control Systems With Adjustable Parameters.J.Ofguidance, Control, And Dynamics 133 (1990),Pp. 404-408.

[6]. K.W. Han, C.C. Liu, Y.T. Wu, Design Of Controllers By Parameter-Space Method And Gain-Phase Margin Tester Method. Proc. Of 1999roc Auto. Control Conf. Yunlin, 1999, Pp. 145-150.

[7]. G.H. Lii, C.H. Chang And K.W. Han, Analysis Of Robust Control Systems Using Stability Equations.J.Ofcontrolsystems And Technology1 1 (1993),Pp. 83-89.

[8]. K.W. Han And G.J. Thaler, Control System Analysis And Design Using A Parameter Space Method.Ieee Trans.Onautomaticcontrol, Ac-11 (3) (1966),Pp. 560-563.

[9]. D.D. Š Iljak, Parameter Space Methods For Robust Control Design: A Guided Tour.Ieeetrans. On Automatic Control34 7 (1989),Pp. 674-688.

[10]. D.D. Ś Iljak, Generation Of The Parameter Plane Method.Ieee Ns.Onautomatic Control11 7 (1997),Pp. 674-688.

[11]. C.T. Huang, M.Y. Lin And M.C. Huang, Tuning Pid Controllers For Processes With Inverse Response Using Artifical Neural Networks.J.Chin. Inst. Chem. Ngrs30 3 (1999),Pp. 223-232.

[12]. D.D. S̆ Iljak, Nonlinear Systems: The Parameter Analysis And Design., John Wiley\& Sons Inc, New York (1969).

[13]. N.S. Nise, Control Systems Engineering. (2nd Ed. Ed.),, Addison-Wiley Lishing Company, 